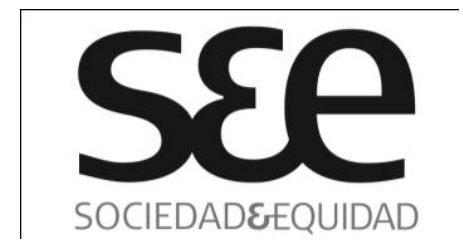

The Bolsa Familia Program and poverty in Brazil: more than numbers to consider

\section{El Programa Bolsa Familia y la pobreza en Brasil: mucho más que números a considerar}

$\begin{array}{ll}\text { Nombre: } & \text { Milene Peixoto Ávila }{ }^{(1)} \\ \text { Filiación: } & \text { Universidad Estadual de Santa } \\ & \text { Cruz (UESC) } \\ \text { País: } & \text { Brasil } \\ \text { Correo: } & \text { mipeixotoavila@yahoo.com.br }\end{array}$

\title{
Resumen
}

El Programa Bolsa Familia (PBF), creado en 2003, se convirtió en el mayor programa de transferencia de ingresos condicionados de Brasil y del mundo, tanto por la cantidad de familias beneficiadas, como por su abultado presupuesto anual. El programa es conocido por gran parte de la población nacional y despierta gran interés político y académico. El presente artículo tiene como objetivo discutir esta política pública en sus diferentes etapas de desarrollo, considerando aspectos institucionales tales como diseño, implementación y modelo de gestión, y aspectos subjetivos: en este caso, la visión que de ella tienen sus destinatarios. Para esto se analizan datos recolectados en una investigación de campo realizada con veinte beneficiarias del PBF, residentes en las ciudades de São Carlos y São Paulo. Usando como metodología la etnografía, la investigación compara las diferencias y semejanzas de los efectos del Programa en las condiciones de vida de los beneficiarios de ambas ciudades, destacando la interacción generada entre esta población y los instrumentos y agentes de la política estudiada. Uno de los efectos observados es que la población destinataria no entiende este beneficio como un

\footnotetext{
${ }^{1}$ La autora es Licenciada y Magister en Ciencias Sociales de la Universidad Federal de São Carlos (UFSCar), Brasil; estudiante de Doctorado en Ciencias Sociales de la Universidad Estadual de Campinas (UNICAMP), Brasil. Además, es Docente de Ciencia Política en la Universidad Estadual de Santa Cruz (UESC), Ilhéus, Bahía, Brasil. Sus líneas de investigación son: pobreza y políticas públicas.
} 


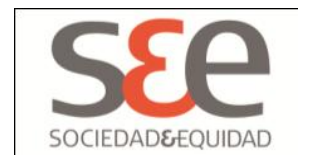

derecho, sino como una ayuda "dada por el gobierno (de turno)" o un "regalo caído del cielo". La población destinataria tampoco se identifica bajo el término de "beneficiario", ampliamente utilizado en los documentos oficiales y trabajos académicos.

\section{Palabras Claves}

Pobreza, Beneficiarios de Políticas Públicas, Evaluación de Políticas Públicas, Transferencia de ingreso, Programa Bolsa Familia.

\section{Abstract}

The Bolsa Família (“Family Bag”) Program (PBF), created in 2003, became the largest conditional transfer income program of Brazil and of the world, due to the number of beneficed families and their increasing budget. This program is known by a large part of the local population and has obtained political and academic interest. The aim of this article is to discuss this public policy in its different stages, considering both: institutional (design, implementation and management model) and subjective aspects ( the vision of the addressees). Ethnographic data collected from a field research performed with twenty PBF beneficiaries living in the cities of São Paulo and São Carlos are analyzed. Differences and similarities regarding the effects of the Program on the beneficiaries living conditions are compared, highlighting the interaction between the target population and the instruments and agents of this policy. One of the observed effects is that the target population does not understand the benefits as a social right, but as an aid "given by the government" or something that "fell from the sky". They also do not identify with the concept of "beneficiary", widely used in official documents and academic papers.

\section{Keywords}

Poverty, Beneficiaries and Evaluation of Public Policies, Transfer Income Programs, Bolsa Familia Program. 


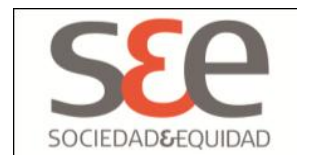

\section{Introducción}

Los programas de transferencia condicionada de ingresos constituyen actualmente una de las principales políticas de protección social, tanto en América Latina ${ }^{2}$ como en otras partes del mundo. En Latinoamérica, las políticas de transferencia de renta surgieron a fines de la década del noventa e inicio del 2000, en un contexto de crisis económica y de necesidad de reformulación del papel social del Estado. Ello de acuerdo a las orientaciones de las políticas de ajustes estructurales definidas por el llamado "Consenso de Washington" y diseminada en forma de "recomendaciones" por el Banco Mundial y el Fondo Monetario Internacional (FMI).

A pesar de sus particularidades y de la diversidad de elementos relacionados a las condiciones de acceso (valor de los beneficios, modelos de gestión y de fiscalización, entre otros tantos), existen algunas semejanzas entre los programas de trasferencia de ingreso implementados. De acuerdo con Ana Fonseca (2010), además del privilegio de la mujer en la titularidad del beneficio, estas políticas tienen en común el hecho de focalizarse en familias pobres con niños y adolescentes, y regirse por el principio de la condicionalidad: esto es, no se constituyen como un derecho sino como beneficios temporarios.

Este tipo de intervención "liberal” - muy influenciada por la teoría de “desarrollo como expansión de las capacidades" - de Amartya Sen (2000), guarda una estrecha relación con la incorporación, en los discursos de los gobiernos y de las agencias multilaterales, de la necesidad de participación activa del "pobre" en el proceso de superación de su condición. Este enfoque implica a su vez fortalecer el capital social y el papel de la mujer en la familia, promoviendo su empoderamiento, autonomía y el desarrollo de sus capacidades. Además, en esta política se destaca la importancia del aumento del consumo de bienes gracias al ingreso extra recibido y la relativa autonomía que el dinero otorga a la mujer dentro del propio núcleo familiar.

Siguiendo esta perspectiva, el programa de transferencia condicionada de ingresos Bolsa Familia se convirtió en la principal política social de Brasil, y ha sido usado como referencia de política en el combate de la pobreza en otros países.

\footnotetext{
${ }^{2}$ En América Latina y en el Caribe, prácticamente todos los países poseen algún tipo de programa de transferencia de renta. En Brasil, este tipo de política fue implementada inicialmente en 1995; en México en 1997; en Nicaragua en el año 2000, aunque sin continuidad; en Colombia también en el año 2000; en Ecuador y Jamaica en 2001; en Argentina y Chile en 2002. En El Salvador, República Dominicana, Perú y Uruguay (en este último extinto en 2008), en 2005; Panamá, Costa Rica y Bolivia en 2006; y Guatemala en 2007 (Fonseca, 2010:7).
} 


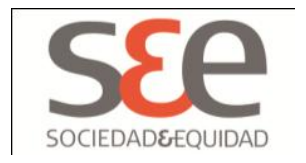

Dicho programa es conocido por gran parte de la población y ha sido objeto de varios estudios, en su mayoría estadísticos.

Al respecto, parece existir una especie de consenso internacional con respecto a la eficacia económica de los programas de transferencia de ingresos. Así por ejemplo, se destaca en el caso brasileño el notorio aumento de ingresos de los sectores más empobrecidos de la sociedad desde 2001 y acentuado a partir del 2003, en contraposición a la estabilidad o caída de los rendimientos de los estratos medios o superiores.

En el caso de la reducción de la pobreza, el estudio realizado por Sergei Soares y colaboradores (2010), muestra que "hubo una disminución de doce puntos porcentuales del número de pobres, que pasó del $26 \%$ al $14 \%$ de la población brasilera. El dinero proveniente del PBF responde por, aproximadamente, el 16\% de esa disminución" (Soares et al., 2010:49). Por su parte, la tasa de extrema pobreza bajó de un $10 \%$ a un $5 \%$, estimándose que un tercio de esta reducción se deriva de la renta transferida a través del PBF.

Si bien la existencia de números favorables da cuenta de la reducción de la pobreza y, en menor proporción, de la desigualdad social en el país, poco se sabe aún sobre las evaluaciones y percepciones que las personas beneficiarias tejen alrededor de este tipo de intervención estatal. Las dimensiones subjetiva y simbólica han sido poco exploradas aún en los estudios sobre políticas públicas. Una de las intenciones de este artículo es discutir, a partir de los datos obtenidos con la investigación etnográfica realizada con beneficiarias del Programa Bolsa Familia $^{3}$, la importancia de estos aspectos, contribuyendo con ello al debate de los elementos presentes en las evaluaciones de programas y políticas sociales.

Además de la Introducción, el presente texto se divide en dos secciones dedicadas al análisis de PBF "de arriba hacia abajo"4 en sus aspectos institucionales, tales

\footnotetext{
${ }^{3}$ Este artículo es producto de la tesis de doctorado de mi autoría, titulada $O$ Bolsa Família e a pobreza no Brasil: 'detalhes' que fazem a diferença, presentada a la Universidade Estadual de Campinas (UNICAMP). Es resultado de una investigación, realizada entre los años 2007 y 2010, con veinte beneficiarias del Programa Bolsa Família, habitantes de las ciudades São Carlos y São Paulo, Brasil.

${ }^{4}$ Referencia a los dos tipos de análisis más comunes de implementación de políticas públicas. El abordaje top-down ("de arriba hacia abajo") considera el análisis del diseño de la política, es decir: el foco es la decisión política, generalmente materializada en leyes, estatutos, reglamentos, para, luego observar, en la implementación, cuáles de los objetivos esperados fueron alcanzados a lo largo del tiempo y por qué. Mientras que el abordaje bottom-up ("de abajo hacia arriba") tiene como punto de partida el contexto en el que se da la implementación de tal política. Al considerar la política en su funcionamiento efectivo, este abordaje reconoce la multiplicidad de actores involucrados a nivel local, con estrategias, intereses y objetivos propios, y muchas veces divergentes a los objetivos legalmente
} 


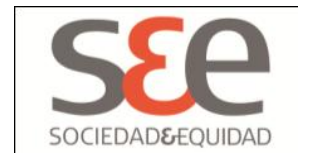

como la definición, el diseño y el modelo de gestión. En otras dos partes del artículo, el Programa se aborda "de abajo hacia arriba", utilizando los datos recaudados durante el trabajo de campo con las beneficiarias del Programa Bolsa Familia, que refieren a sus percepciones y evaluaciones personales sobre el mismo. Por último, el artículo presenta algunas conclusiones.

\section{El Programa Bolsa Familia: en qué consiste y algunos datos}

En menos de diez años de implementación el Programa Bolsa Familia se convirtió en el mayor programa de transferencia de ingresos de Brasil y del mundo. Aquello debido a la cantidad de familias atendidas - $13.394 .893^{5}$ en mayo de 2012 , con la previsión de ampliar la población beneficiaria ${ }^{6}$ prevista hasta el año 2013 a 13,8 millones -, como al presupuesto destinado que hasta abril de 2012 fue de R\$ 6.307.630.009,007 . Es decir, más de US\$ 3,1 billones.

Creado en el año 2003, el PBF fue pensado para unificar los programas de transferencia de ingresos existentes a nivel nacional en Brasil, que fueron inaugurados durante la gestión de Fernando Henrique Cardoso (1995-2002): Programa Bolsa Escola, Auxílio-Gás, Bolsa Alimentação y Cartão Alimentação. Con esta unificación, se buscó integrar los diferentes programas de transferencia de ingresos existentes hasta el momento, evitando así la duplicidad de esfuerzos por parte del gobierno nacional, racionalizando los costos operativos y centrando la política social en el grupo familiar para combatir la pobreza (Silva, Yazbek y Di Giovanni, 2004).

Oficialmente, es definido como "un programa de transferencia directamente para las familias pobres y extremadamente pobres, que vincula el recibimiento de auxilio financiero al cumplimiento de los compromisos (condicionalidades) en las áreas de educación y salud" (MDS, 2005:13). De acuerdo con el Art. $4^{\circ}$, del Decreto $N^{\circ} 5.209 / 04$, el PBF tiene cinco objetivos básicos:

formulados institucionalmente. Ellos pueden ser altamente influyentes en los efectos producidos por la política pública.

${ }^{5}$ La población total brasileña, según el censo IBGE 2010, es de 190.755.799 personas. De la cual, más de 13,5 millones de familias reciben el Programa Bolsa Família.

${ }^{6}$ De acuerdo con el censo IBGE de 2010, la estimativa de familias en el perfil del Programa Bolsa Família es de 13.738.415.

${ }^{7}$ Este valor representa, en 2012, al 0,46\% del PBI brasileño. 


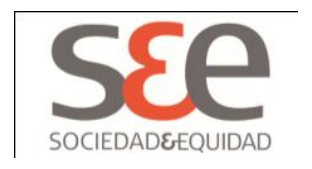

1) Promover el acceso a la red de servicios públicos, en especial, de salud, educación y asistencia social;

2) Combatir el hambre y promover la seguridad alimenticia y nutricional;

3) Estimular la emancipación sustentada de las familias que viven en situación de pobreza y de extrema pobreza;

4) Combatir la pobreza;

5) Promover la inter-sectorialidad, la complementariedad y la sinergia de las acciones sociales del Poder Público.

Siguiendo estos preceptos, el PBF transfiere ingresos, prioritariamente a las mujeres, mediante la exigencia de condiciones vinculadas a la educación y al cuidado de la salud de niños y adolescentes. El objetivo de las condiciones, según el documento oficial del Programa, "es contribuir y ampliar el acceso de las familias excluidas a los servicios de salud y de educación, con la posibilidad de contribuir para la reducción de la pobreza en la próxima generación" (Baratta, 2008:188). En términos de la teoría causal del problema a resolver - la pobreza y la extrema pobreza-, este movimiento doble puede ser visto como innovador, porque pretende actuar a través de diferentes medios y en sus diferentes etapas, combatiendo la pobreza de hoy y de mañana.

Al contrario de la jubilación y del seguro por desempleo, el PBF es una política de distribución de ingreso no contributiva ${ }^{8}$. Es decir, las personas reciben ingresos que no debieron financiar previamente? ${ }^{9}$ Tampoco es un derecho adquirido sino un beneficio que debe ser revisado cada dos años ${ }^{10}$. Está, pues, a

\footnotetext{
${ }^{8}$ Otros ejemplos de programas de transferencia de ingresos no contributivos, además del Programa Bolsa Família, son: el Beneficio de Prestação Continuada (BPC), instaurado en 1996 y la Previdência Rural, implantada en 1991.

${ }^{9}$ Gran parte del presupuesto del Bolsa Família proviene del presupuesto de Seguridad Social, vía COFINS (Contribução para o Financiamento da Seguridade Social). Otra parte se deriva de préstamos del Banco Mundial al gobierno brasileño.

${ }^{10}$ Conforme al Art. 21 del Decreto n 6.392 del 12 de marzo de 2008: "la concesión de los beneficios del Programa Bolsa Família tiene carácter temporal y no genera derecho adquirido, por lo que la elegibilidad de las familias debe ser obligatoriamente revisada en un período de cada dos años para recibir tales beneficios".
} 


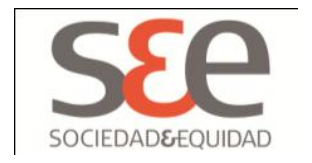

merced de cortes o incrementos presupuestarios definidos por el gobierno nacional cada año ${ }^{11}$.

En términos de cobertura de atención, como política pública, el Programa Bolsa Família solamente se sitúa por debajo de la educación pública, del Sistema Único de Saúde (SUS) y de la Previdência Social. Realizando un seguimiento de la implementación del Programa, es imposible no percibir la expansión gradual del presupuesto y del público- objetivo, además de modificaciones en los valores pagados y el aumento de nuevas metas.

Estimando que en el año 2003 existía un número de 11.206.212 pobres y extremadamente pobres en Brasil, el PBF, ya en el año de su creación, atendió a 3,6 millones de familias con un presupuesto de $\mathrm{R} \$ 4,3$ billones. Con una meta de 11,2 millones de familias, en el año 2004, el PBF estuvo presente en 5.533 municipios (con un 99,5 \% de cobertura), llegando a 6.571 .842 familias y ampliando el presupuesto a R\$5,3 billones. En 2005, el Programa abarcó el 100\% de los municipios brasileños, llegando a 8 millones de familias con un presupuesto de $\mathrm{R} \$ 6,5$ billones. A fines del año 2006, la meta final es lograda - 11.120.363 familias atendidas-, hecho que exigió la ampliación del presupuesto a $\mathrm{R} \$ 8,3$ billones y el establecimiento de nuevas metas. Actualmente, y hasta el año 2013, se estipula la atención de 13,8 millones de familias.

Con relación a los efectos más visibles del Programa, además del aumento de los ingresos de las familias pobres y extremamente pobres, los estudios muestran que el beneficio del PBF es destinado al cuidado y bienestar de los niños a través del aumento del consumo de alimentos y otros bienes necesarios para la población infantil $^{12}$.

\footnotetext{
${ }^{11}$ La ley que crea el PBF declara que: "el Poder Ejecutivo deberá compatibilizar la cantidad de beneficiarios del Programa Bolsa Família con las dotaciones presupuestarias existentes" (Art. 6, párrafo único, Ley no 10.836, del 9 de enero de 2004).

12 De acuerdo con la investigación hecha en 2008 por el Instituto Brasileiro de Análises Sociais e Econômicas (IBASE), 87\% de los beneficiarios del Programa Bolsa Família utilizan el beneficio para la adquisición de alimentos; mientras que $46 \%$ lo utilizan para compra de materiales escolares y $37 \%$ para la adquisición de vestuario para niños.
} 


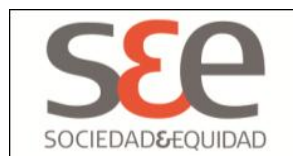

Aspectos Institucionales: definiendo las “reglas de juego"

Al tratarse de una política focalizada, es decir, no accesible a todos los brasileros, fueron adoptados criterios de elegibilidad. El criterio de definición de pobreza y de extrema pobreza adoptado por el Estado brasilero tiene como base, exclusivamente, el ingreso per cápita mensual de la familia, que se define como "la suma de los rendimientos brutos recibidos mensualmente por la totalidad de los miembros de la familia, excluyéndose del cálculo los rendimientos concedidos por programas de transferencia de ingreso" (MDS, 2005:13).

Por lo anterior, el PBF está destinado a personas clasificadas en el Cadastro Único $^{13}$ como pobres o extremadamente pobres ${ }^{14}$. Además de la cuestión del ingreso, están incluidos grupos de personas tradicionalmente excluidos de las políticas sociales, tales como: personas que viven en asentamientos rurales, en la calle, en pueblos o comunidades tradicionales (quilombolas y territorios indígenas).

En relación a la transferencia de ingreso, el PBF posee cinco tipos de

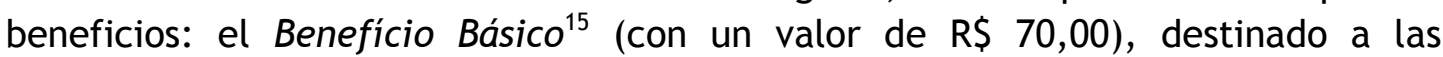
familias consideradas extremadamente pobres. Cada familia puede recibir sólo un Benefício Básico. El Beneficio Variável (R\$ 32,00) es otorgado a las familias pobres o de extrema pobreza que tengan entre sus miembros a niños y adolescentes entre 0 y 15 años, gestantes ${ }^{16}$ y/o lactantes ${ }^{17}$. Cada familia puede recibir hasta cinco

${ }^{13}$ El CadÚnico o Cadastro Único para Programas Sociais es un instrumento de recolección de datos que identifica las familias de bajos ingresos y sus principales vulnerabilidades, garantizando una correcta selección de aquellas que deben ser beneficiadas por los programas sociales (MDS, 2011).

${ }^{14}$ El criterio de definición de pobreza y de extrema pobreza adoptado en Brasil es el ingreso; o sea, son consideradas "pobres" las familias que tienen un ingreso per cápita de hasta R \$140,00 (más o menos 85,5 dólares). Las familias clasificadas como extremadamente pobres son aquellas que tienen el ingreso per cápita mensual de hasta $\mathrm{R} \$ 70,00$ (aproximadamente 43,00 dólares).

${ }^{15}$ Es importante destacar que este es el único beneficio del PBF atribuido a familias sin hijos, porque a pesar de que el Programa está vinculado al cumplimiento de condicionalidades referentes a la educación y a la salud de niños y adolescentes, se justifica el pago del Benefício Básico a las familias sin hijos en función de su condición de extrema pobreza. Las familias en condición de extrema pobreza, con niños y adolescentes pueden recibir, además del Benefício Básico, el Benefício Variável, en caso de que tengan niños entre 0 y 15 años; el Beneficio de Superação da Extrema Pobreza na Primeira Infância, en caso de tener niños entre 0 y 6 años y el BVJ, si tienen hijos adolescentes.

${ }^{16}$ El Benefício Variável Gestante está vinculado al Número de Identificação Social (NIS) de la gestante beneficiaria del PFB, pudiendo ser concedido más de un beneficio en la misma familia, 


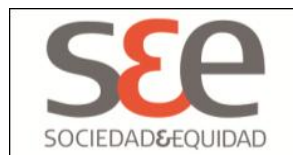

Benefícios Variáveis, o sea, hasta R\$160,00. Existe además un beneficio destinado a los adolescentes: el Benefício Variável Jovem (BVJ), con un valor de R\$38,00, otorgado a todas las familias del Programa que tengan adolescentes de 16 o 17 años y que asistan a la escuela. Cada familia puede recibir hasta dos BVJs, o sea, hasta $\mathrm{R} \$ 76,00^{18}$. Una adolescente que reciba el Benefício Variável Jovem (BVJ) puede recibir también el Benefício Variável Gestante. Otra modalidad es el Benefício Variável de Caráter Extraordinário (BVCE), otorgado en los casos en que el cambio de la familia desde los Programas complementarios (Auxílio-Gás, Bolsa Escola, Bolsa Alimentação e Cartão Alimentação) al PBF, les cause pérdidas financieras. El valor del beneficio se calcula caso a caso.

El 14 de mayo de 2012, durante la gestión de la presidenta Dilma Rousseff, se creó un nuevo beneficio - el Benefício de Superação da Extrema Pobreza na Primeira Infância - que completa los valores del PBF para familias ya beneficiarias, pero que aún están en situación de extrema pobreza y que tienen entre sus miembros niños de entre 0 y 6 años. Este nuevo beneficio, como su nombre indica, tiene como objetivo combatir la extrema pobreza entre las familias beneficiarias del Programa, cuyo ingreso mensual es inferior a $\mathrm{R} \$ 70,00$ por integrante de la unidad familiar. Su valor no es fijo sino variable, en tanto tiene un carácter de complemento del ingreso otorgado por el PBF para que éste corresponda como renta familiar a la suma de $\mathrm{R} \$ 70,00$ per cápita.

A pesar de ser una política creada por el gobierno nacional, la gestión del PBF es descentralizada. Es decir, es compartida entre el gobierno nacional y los gobiernos provinciales y municipales. Sin embargo, la Senarc (Secretaria Nacional de Renda de Cidadania), vinculada al MDS (Ministério de Desenvolvimento Social e Combate à Fome), es la institución responsable por el Programa y por las demás iniciativas de transferencia de ingresos. El gobierno nacional envía fondos a los

siempre que no ultrapase el máximo de cinco Benefícios Variáveis. La interrupción del pago del Benefício Variável a la gestante ocurrirá automáticamente, luego de las nueve cuotas correspondientes a los meses de embarazo.

${ }^{17}$ El Benefício Básico Variável Nutriz (BVN) está destinado a las familias que tengan niños con hasta seis meses de vida. El objetivo de este beneficio es garantizar mejores condiciones de nutrición a la madre y al bebé, sirviendo de auxilio a la promoción de la seguridad alimentaria y nutricional, considerando la importancia del amamantamiento en los primeros seis meses de vida del niño.

${ }^{18}$ Estos valores corresponden al reajuste anunciado el $1^{\mathrm{o}}$ de marzo de 2011 , durante la gestión de la presidenta Dilma Rousseff y entraron en vigor en abril de 2011. 


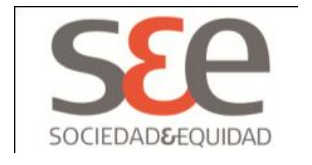

gobiernos locales y éstos deben hacer funcionar en la práctica esta política, por medio de las instituciones asistenciales. Al firmar el Termo de Adesão, el municipio se compromete a registrar en el Cadastro Único a los posibles beneficiarios, ejecutar y fiscalizar el PBF. Además, es competencia de la intendencia de cada ciudad el poner en práctica formas de control y de participación social, estableciendo el Consejo Social del Programa Bolsa Família.

Dentro de los municipios, el órgano responsable por el PBF es la institución de asistencia social, en general la Secretaria Municipal de Assistência Social. Cabe al gestor municipal un papel fundamental de control, establecimiento de las directrices del Programa y la gestión de los beneficios. El gestor municipal tiene el poder de decisión sobre dónde y cómo se hará el registro ${ }^{19}$ de los beneficiarios. Así mismo, tiene el poder de inclusión o exclusión en el Sicon (Sistema de Gestão de Condicionalidades do Programa Bolsa Família), y acceso a la información del Cadastro Único de las familias beneficiadas. La alteración de los registros es una de las principales acciones del municipio en el proceso de gestión de los beneficios, que consiste en el bloqueo, desbloqueo, cancelación, reversión de la cancelación y suspensión de los beneficios.

Como es competencia de los gobiernos municipales la ejecución y fiscalización del PBF, es posible afirmar que, en cada ciudad, la implementación del Programa se realizará de una forma específica. Es decir, el gobierno nacional envía fondos y directrices a los municipios, y éstos implementarán el PBF de acuerdo con la estructura de asistencia social que poseen. Como resultado de esta gestión descentralizada, los procesos relacionados con el funcionamiento del Programa $^{20}$ difieren de ciudad a ciudad, pudiendo reconocerse diferencias y semejanzas en la implementación de la política.

En la siguiente sección se expondrán los resultados empíricos obtenidos a través del trabajo de campo realizado con técnicos responsables del PBF y algunas beneficiarias de las ciudades de São Paulo y São Carlos (interior del Estado de São

\footnotetext{
${ }^{19}$ El proceso de inclusión de los datos de las familias en el Cadastro Único y, consecuentemente, en el Programa Bolsa Família, no se realiza de la misma forma en todo Brasil. En la ciudad de São Paulo, por ejemplo, el registro no es continuo, pues es realizado parcialmente de forma domiciliaria en combinación con puestos ambulantes de recopilación de datos, creados ad-hoc para tal finalidad.

${ }^{20}$ De entre estos procesos que varían de municipio a municipio, se destacan los vinculados a la definición de cómo se realiza el registro de datos en el Cadastro Único (o sea, la entrada del beneficiario en la política) y el tipo de actividades o programas complementarios ofrecidos a los beneficiarios.
} 


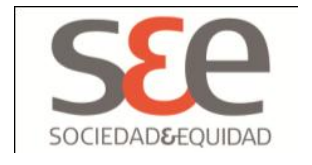

Paulo), en el transcurso de los años 2007 a 2010. A través del uso de la etnografía como método de recolección y análisis de los datos, el objetivo fue comprender el "encuentro" de la política con la subjetividad de las personas; es decir, aprehender la interacción entre el Programa Bolsa Família y la población beneficiaria, observando los efectos políticos y subjetivos generados en esta última.

Al distanciarnos de la mirada que hemos denominado de "arriba hacia abajo" -y cuyo análisis hemos realizado en las secciones anteriores-, la perspectiva de "abajo hacia arriba" hace aparecer algunos detalles sobre la implementación del Programa Bolsa Família que las definiciones y las metas oficiales no ofrecen. Cuestiones como la inclusión en la política, la diferencia de los valores recibidos, la dificultad de informaciones respecto del Programa, toman cuerpo y asumen diferencias y semejanzas en cada región estudiada.

\section{El Programa Bolsa Família "de abajo hacia arriba"}

Al salir "del papel” y ser implementado, el Programa Bolsa Família comienza a funcionar efectivamente y a interactuar con las personas. La implementación es la etapa del proceso de producción de políticas públicas en el cual el problema público que ha sido detectado (en este caso, la pobreza), tiene una solución formulada y regulada, para luego ser llevada a la práctica. Ese sería, para Bo Rothstein (1998), el momento de la verdad de la política: es decir, cuando ésta se torna concreta para el ciudadano. Ello porque, para este autor, toda política pública tiene una acción reflexiva, que despierta sentimientos y comportamientos en los individuos directa o indirectamente ligados a ella; y genera, por lo mismo, conflictos de opiniones y de intereses.

De esta forma, dejando de lado los números y considerando el Programa desde la óptica de los que están "dentro de la política”, los elementos simbólicos y las representaciones de los diferentes actores involucrados en los procesos de ejecución de la política surgen como puntos interesantes para la evaluación del diseño, de la organización burocrática, de los resultados y, principalmente, de la legitimidad de dicha política. A través de entrevistas con técnicas/os responsables por el PBF a nivel municipal, y del seguimiento de algunas actividades y reuniones desarrolladas por las instituciones asistenciales de las ciudades de São Paulo y São Carlos, fue posible realizar un relevamiento sobre el funcionamiento del Programa. 


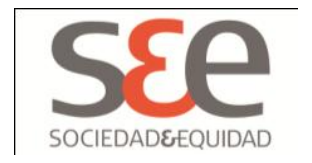

En el contexto cotidiano del PBF, la forma como se realizan los registros puede ser un buen ejemplo para analizar las diferentes maneras que asume la política al ser implementada por el municipio, tanto como para analizar las percepciones que puede despertar en las personas. Aunque exista la tendencia a concentrar los registros de las familias en los Centros de Referência em Assistência Social (CRAS), esto no ocurre en todos los municipios. En el caso de São Paulo, que es una ciudad de grandes proporciones territoriales y demográficas, según Rafael Tartaroti $^{21}$, la intendencia no cuenta con una estructura para realizar, de una sola vez, los registros de la cantidad de personas que están en el perfil del PBF $^{22}$. En la cuidad de São Paulo no existe un punto fijo de registro para los programas de transferencia de ingresos, es decir, un lugar específico a dónde la población pueda dirigirse. Tampoco se realiza el registro de manera continua.

De acuerdo con el técnico responsable por la gestión de los beneficios del PBF en São Paulo, "no hay un lugar fijo para realizar los registros del Bolsa Familia. Cuando queremos hacer una acción de registro abrimos una licitación. Después contratamos una empresa privada que alquila unas casas y monta puestos de registro. Después que vence el contrato, necesitamos abrir otra licitación”. Los primeros registros en el PBF fueron realizadas a través de visitas domiciliarias, por agentes contratados para tal finalidad. Actualmente los registros son semidomiciliares: se avisa a las familias "por carta, en los medios de comunicación, llamando al teléfono 156, o en el bus de la SPTrans” (Rafael) el día y la hora en que deben comparecer al lugar en donde se efectuará el registro.

En la práctica, la forma en que se estructuran los registros genera efectos negativos en la población demandante, ya que, al no encontrar un espacio definido para dirigirse, y desconociendo con quién debe conversar para informarse sobre el PBF y los demás programas de transferencia de ingresos existentes en la cuidad, asume una postura pasiva. Hay que esperar entonces las visitas de los agentes o una carta que convoque para el registro. Con esto, muchas familias dentro del perfil de Bolsa Familía están sin acceso a dicha política, hecho que genera en este sector de la población el sentimiento de que el "Bolsa Família sólo llega a quienes no lo necesitan".

\footnotetext{
${ }^{21}$ Técnico responsable por el Programa Bolsa Família en la Coordenadoria de Gestão de Benefícios (CGB), perteneciente a la Secretaria Municipal de Assistência Social de la Intendencia de la cuidad de São Paulo.

${ }^{22}$ En el momento de las entrevistas (12/02/2010), de acuerdo con Rafael Tartaroti, había casi 170.000 familias registradas en el Programa Bolsa Família.
} 


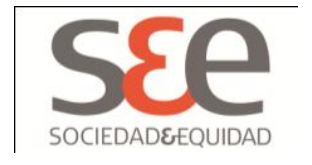

A diferencia de lo que ocurre en São Paulo, donde existe una especie de "burocracia sin rostro", en la ciudad de São Carlos la población identifica los Centros Comunitários, a sus técnicos y a la Secretaria Municipal de Cidadania e Assistência Social como fuentes de esclarecimiento de dudas sobre el PBF y sobre los registros. Más aún, es común la actitud de personificar la concesión de los beneficios, de acuerdo a lo observado en el discurso de algunos beneficiarios:

Fue Fernanda quien hizo mi registro. Fue ella quien lo consiguió. (María Auxiliadora, ama de casa y madre de dos niños beneficiaria del PBF).

Yo recibía $\mathrm{R} \$ 95,00$ todos los meses, pero cuando fui a recibir no había más. Fui a hablar con Doña Eliana [asistente social del CRAS] pero ella no resolvió nada. Entonces fui hasta el centro [en la Secretaria Municipal de Cidadania e Assistência Social] para hablar con César y él me resolvió el problema. Me dijo que era porque yo tenía dos registros. Después de un tiempo volví a recibir. (Rosimeire, ama de casa, madre de dos hijos).

La consejera Silvana fue quien consiguió mi registro. Yo fui hasta ella, la conozco hace más de 12 años, ya trabajé mucho para ella. Le expliqué la situación y ella me dio un papel y me mandó a que venga aquí a hablar con Doña Eliana. Vine aquí [al CRAS] a fines de noviembre, y comencé a recibir el Cartão Alimentação en diciembre. Pero el Bolsa Família demora más, comencé a recibirlo ahora, sólo recibí una cuota. Me parece que ella [la consejera] cumplió con su obligación de ayudarme, porque ella es consejera y ya que ella está ahí, tiene que ayudar a las personas. (Marcos, desempleado, padre de dos niños beneficiario de los programas Bolsa Família y Cartão Alimentação). 


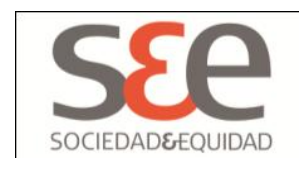

Es interesante resaltar que ese proceso de personalización está relacionado con la concesión, es decir, con la entrada en la política del PBF, pero no se extiende al pago del beneficio. O sea, es el técnico/a quien "abre las puertas" para que las personas entren en esta política, pero quien paga es "el gobierno", como me explicó Josiane: "Yo no recibo de la asistente social, recibo del gobierno".

Podemos apreciar en estos relatos que en la sociedad brasilera está clara la noción de ciudadanía corriente. De acuerdo con Vera Telles (2001), en Brasil, los derechos son concebidos como privilegios o favores, es decir, "bondad del dador". Eso ocurre porque

[...] los derechos nunca fueran formulados según una noción de igualdad, pero según la óptica de la protección que un Estado benevolente debe a los débiles e indefensos; en que, para utilizar la formulación precisa de Marilena Chauí (1987), las diferencias sociales son transformadas en jerarquías que crean la figura del subalterno que tiene el deber de obediencia y del inferior que merece la tutela, la protección, el favor, pero jamás los derechos (Telles, 2001: 59).

Así, para algunas beneficiarias, empezar a recibir una política pública no es resultado de una desventaja en las condiciones sociales, sino el resultado de la eficiencia o de la buena voluntad de los agentes gubernamentales. Esa noción de justicia social está presente también en las percepciones y evaluaciones que los beneficiarios tienen sobre el PBF, según veremos a continuación.

\section{Algunas percepciones de los beneficiarios sobre el Programa}

A través de charlas informales con las beneficiarias, se buscó entender qué conocimientos tenían ellas sobre el funcionamiento del PBF; cómo se sentían frente al hecho de recibir todos los meses ingresos que proviene del gobierno y no de un trabajo remunerado; cómo comprendían la condición de pobreza que viven; además de indagar si la interacción de las beneficiarias con el Programa Bolsa Família generó algún efecto político en sus vidas.

Una de la cuestiones es que el término “beneficiaria”, ampliamente utilizado por el gobierno nacional, por los medios masivos de comunicación y por 


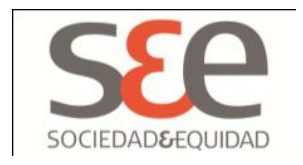

quienes estudian el tema, sencillamente no tiene ningún significado entre las personas clasificadas de este modo. Las titulares del PBF no asimilaron este término en su cotidianeidad: ellas no se reconocen como beneficiaras, ellas simplemente "tienen el Bolsa"

Lo mismo fue observado por Cleonice Araújo (2007) en su estudio sobre las concepciones de pobreza presentes en los programas de transferencia de ingresos. Según esta autora, las personas "no se autodenominan como beneficiarias. Al contrario, muchas demostraron desconocer esa designación con la cual no se identifican" (Araújo, 2007:36). Sin embargo, no utilizar el término oficial para auto-clasificarse no significa, necesariamente, que ellas no se identifican, de alguna forma, con el Programa Bolsa Família. Como me explicó Josiane, beneficiaria del PBF de São Carlos: "yo me siento parte del Bolsa Família. No siento vergüenza ni soy la única que lo recibo. Aquí mismo hay un par de gente que lo recibe".

Tal vez, la explicación para la no asimilación de este término en el vocabulario de las beneficiarias, tenga que ver con el poco contacto con los documentos y estudios sobre el Programa y con la baja frecuencia en la oferta de reuniones socioeducativas sobre el Programa Bolsa Família. A pesar de existir una gran producción de materiales explicativos y evaluativos sobre el Bolsa Família, condensados y accesibles, en el sitio del MDS por ejemplo; este material no es de hecho accesible ni está disponible para las personas beneficiadas por esta política. Existen muchas lagunas y fallas en la comunicación entre el público que la recibe y la gestión local o nacional del PBF.

Además de no identificarse con el término clasificatorio "oficial", las beneficiarias de São Carlos y São Paulo no se identifican automáticamente y en todo momento con el status de "pobre". La condición de pobreza, a pesar de ser el factor determinante que justifica la entrada y la permanencia de la familia en el Programa Bolsa Família, no es admitida de forma directa por las beneficiarias. Cuando se les preguntó por qué recibían el Bolsa Família, ninguna de ellas respondió que era por "ser pobre" 23 , condición de entrada en esta política. La justificación para ser beneficiaria del Programa no se basaba en la afirmación

\footnotetext{
${ }^{23}$ La tesis de Maestría en Sociología de Maria de Fátima Pereira "As representações da pobreza sob a ótica dos 'pobres' do Programa Bolsa Família", defendida en el 2007, es un interesante estudio sobre cómo las beneficiarias del Programa Bolsa Família de la ciudad de Fortaleza, en el momento de hacer los registros en el Cadastro Único, interpretan o representan el papel de "ser pobre" para convencer a los técnicos responsables de que realmente son pobres y que merecen continuar recibiendo el beneficio del Bolsa Família.
} 


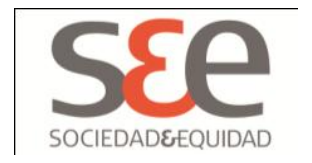

directa de la condición de pobreza. Oscilaba entre el reconocimiento de la necesidad y el hecho de ser madre de niños pequeños que están estudiando. Durante el trabajo de campo realizado en las casas de las beneficiarias, en ningún caso fue escuchada la autoafirmación "soy pobre, por eso recibo el Bolsa Família". La categoría pobreza se mostró relativa y descubrimos que autodenominarse como pobre no es tan simple y objetivo como puede serlo para quienes estudian el fenómeno. Para las personas consideradas pobres por el Estado, no siempre es automático asumirse como pobre, sino que muchas veces puede resultar vergonzoso ${ }^{24}$. Sin embargo, hay otros momentos en los cuales es necesario afirmar e incluso enfatizar, y hasta representar, el hecho de ser pobre. Como cuando se está frente a un trabajador social ${ }^{25}$ que tiene el poder de incluir los datos en el Cadastro Único y conceder algún tipo de beneficio.

Otro punto que resultó interesante es que el PBF no es concebido como una política pública para gran parte de las beneficiarias escuchadas, destinada a las familias que no logran alcanzar un ingreso mensual mínimo. El programa es visto, más bien, como un regalo que se gana por suerte, por bendición de Dios o porque se está "necesitando". Las beneficiarias comparten la opinión generalizada en la sociedad brasilera de que los derechos son privilegios. Esto constituye la base de la concepción de justicia social, que

es una noción de justicia que se elabora en el interior de un universo moral, en el cual las diferencias entre las personas son percibidas a través de categorías éticas, de diferencias del poder, de prestigio y de riqueza, siendo juzgadas por referencia a las cualidades y vicios de los hombres en las relaciones con las cosas y personas. Es un universo moral que se articula con las esperanzas de redención

\footnotetext{
${ }^{24}$ Prácticamente todas las veces que se preguntaba directamente a alguien si era pobre, durante la entrevista, la reacción era de vergüenza, seguida de negación. Hacer esa pregunta era un momento incómodo durante la entrevista.

${ }^{25}$ Aquí vale la pena comentar la forma como Maísa, beneficiaria del Bolsa Família de la ciudad de São Carlos, entró en el Programa. "Yo fui allá a Champagnat [lugar donde se realizan los registros] a hablar con la trabajadora social. Llegué, todo bien. Cuando me senté frente a ella y coloqué la cartera sobre las piernas, pensé, ¡uy! ella va a ver que es de cuero [la cartera]. Coloqué rapidito la cartera debajo de la silla. Y ahí conté una súper historia. Dije que era pobre, que tenía dos hijos, que mi marido me había abandonado y que sólo conseguía trabajar limpiando fuera de casa dos veces por semana y que no ganaba casi nada. Salió todo bien" (Maísa). Lo interesante es que Maísa estaba mintiendo, porque ella trabaja todos los días, está casada y su marido tiene un empleo formal. Para Maísa, la mentira se justificaba porque ella y su familia "precisan" del dinero proveniente del PBF.
} 


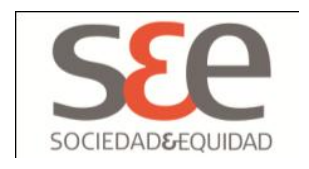

alimentadas en la creencia de una Providencia como instrumento del bien y de la justicia en el mundo de los hombres. [...] Es en esta articulación que se eleva la expectativa de que surja una voluntad generosa, capaz de resolver la paradoja ética de la virtud no recompensada y de la victoria de la injusticia, restableciendo los equilibrios morales rotos por la maldad, la avaricia y codicia de los hombres (Telles, 2001: 86).

Así, los derechos o los beneficios de una política pública, son concebidos como un regalo que "se gana" y que se "pierde", y que alguien lo da: "el gobierno", “Dios”, el trabajador social. Es, pues, un privilegio o suerte de aquellos que "logran" entrar en la política.

Las beneficiarias de las dos ciudades estudiadas, en general, no comprenden el beneficio como un derecho vinculado a la condición de ciudadanía. El beneficio es entendido como "una ayuda del gobierno" o bien, como lo señalan a menudo las beneficiarias, algo que "cayó del cielo".

No creo que es un derecho, porque solo dura el tiempo que ellos quieren. Porque ellos dicen que cuando cambie el gobierno, [el PBF] se va a acabar. (Nerci, 28 años, casada, madre de dos niños, habitante de San Carlos, beneficiaria del Bolsa Família).

Este dinero cayó del cielo, porque en ese momento yo no estaba recibiendo nada. Fue Dios quien, en ese momento, mandó a Judith para que me registre. Ese dinero para mí, es una bendición (Sandra, beneficiaria del Bolsa Família).

A mí me parece que es una bendición que cayó del cielo, porque el día que llegó la tarjeta [del Bolsa Família] yo estaba sentada, sin gas, sin tener qué comer. Entonces llegó el correo diciendo que yo tenía un dinero para recibir allá en el banco. Yo no podía creerlo, fue como un milagro realmente. Desde entonces estoy recibiendo 


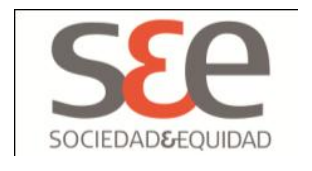

todos los meses, no falla. (Maria da Conceição, desempleada, madre de cinco hijos).

En relación al uso del dinero, las entrevistadas concuerdan al afirmar que el beneficio es de los hijos y que, por eso mismo, debe ser gastado en productos para ellos. Esto se traduce, muchas veces, en la compra de comida que le gusta a los chicos (yogurt galletas, golosinas) o en la adquisición de ropa o artículos escolares. Sobre el uso del dinero, los beneficiarios afirman:

No da para comprar todo. La verdad es que compro algunas de las cosas que ellos [los hijos] necesitan. Ese dinero ayuda para eso. Hay personas que no saben agradecer. Reclaman que es poco, pero fue Dios quien lo mandó. (Sandra).

Yo compro un mes una cosa... lo que ellos [los hijos] están necesitando más. Si están necesitando zapatos, lo compro un mes y después, en el otro, veo que están necesitando. Compro cosas para la escuela. Voy haciendo así, porque tampoco da para comprar todo de una vez, ¿no? (Silvana).

Es poco, pero ayuda. Aunque yo no estoy trabajando, no me quedo con ese dinero para mí. No tiene sentido agarrar ese dinero y salir de farra. El dinero del Cartão Alimantação y del Bolsa Família, ese dinero es de ellas. Compro algunas cosas que ellas están necesitando. El mes pasado compré el uniforme de la bebé. Si ellas no lo están necesitando, guardo el dinero (Marcos).

Con el dinero compro alguna cosa que ellos [los hijos] tienen ganas de comer, un bombón, unas galletas, esas cosas. Un par de chinelas, cuando están faltando (Daniela). 


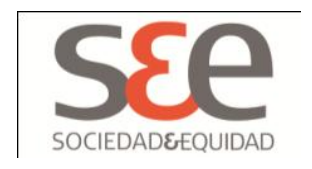

En lo que respecta a las evaluaciones y percepciones de las beneficiarias, hay elementos recurrentes en las ciudades estudiadas, tales como evaluaciones positivas, dudas o quejas sobre el PBF. Tanto en São Carlos como en São Paulo, la evaluación del Programa es generalmente muy positiva y el sentimiento predominante entre las beneficiarias es de agradecimiento.

¡Le daría una nota 10 o más! Porque es muy bueno, ayuda a mucha gente que lo necesita, que pasa hambre. Para mí, cayó del cielo. El gobierno que creó ese beneficio merece ser felicitado (Sandra).

Otros relatos realzan la visión positiva y esbozan un argumento en defensa del Programa contra aquellas que "sólo reclaman":

Para mí es muy bueno porque recibo $\mathrm{R} \$ 95,00 ; \mathrm{R} \$ 45,00$ [del Bolsa Família] y R\$ 50,00 de Fome Zero (Josiane).

Hay gente que reclaman del valor, pero uno no está trabajando ni esforzándose y recibe un dinero y aún así reclama (Alexandra, madre de cinco niños, casada, desempleada, habitante de São Paulo).

Hay gente que no sabe agradecer, reclama que es poco (Maria, desempleada, madre de dos niños, habitante de São Paulo).

Las principales críticas al PBF realizadas por las beneficiarias están relacionadas con la diferencia en los valores pagos. La existencia de diferencias de valores y el hecho de no entender cómo se calcula el valor del beneficio recibido son cuestiones que generan críticas entre las beneficiarias, que comparan los valores recibidos. En general, las beneficiarias consideran "injusto" que cada familia reciba un valor diferente, y es muy común que se pregunten y juzguen "si la familia realmente lo necesita". 


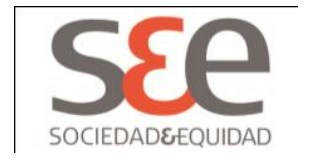

Sônia, habitante de São Paulo, es beneficiaria por dos hijos adolescentes. Recibía en marzo de 2010, un beneficio de R\$ 66,00. Su hermana, que vive en São Luis, es madre de nueve hijos pequeños y recibía un beneficio del PBF con un valor de R\$ 124,00. Para Sônia, su hermana recibe más que ella porque "allá en el Norte, las personas reciben más que aquí".

\section{Entrevistadora: “¿Y por qué?”}

Sônia: "Porque ellos lo necesitan más".

La explicación que Sônia formuló para justificar la diferencia en los valores recibidos se fundamenta, no en la cantidad de hijos -como ocurre de hecho en el diseño de esta política-, sino en la posición geográfica y en el grado de necesidad por el que atraviesan las personas que viven en la región Norte y Nordeste del país. Su interpretación se basa no en el conocimiento de las reglas y del diseño del Programa Bolsa Família, sino en su experiencia de vida. Ella, que nació en el estado de Maranhão, pasó por muchas necesidades económicas, tuvo que migrar a la cuidad de São Paulo donde vive hace más de veinte años. Actualmente trabaja legalmente como agente comunitaria de salud, hecho que la lleva a considerar que está en una situación más favorable que la de su hermana, quien además de no "trabajar afuera", "precisa más" que ella del "dinero del Bolsa".

A continuación, incorporamos otros relatos que muestran la opinión de algunas beneficiarias con respecto a la diferencia de valores pagados por el PBF:

Hay gente que gana más que yo. El marido trabaja y la mujer también y aún así gana más que yo (Daniela, ama de casa, madre de cinco niños, habitante de São Carlos)

Hay gente que ni tiene hijos, está jubilada y recibe más que yo, que tengo cinco hijos pequeños (Cícera, 37 años, madre de cuatro hijos, desempleada, habitante de São Paulo).

El Programa es bueno, pero para mí está mal repartido. Porque unos ganan $\mathrm{R} \$ 120,00$ y otros $\mathrm{R} \$ 90,00$. Entonces no hay acuerdo. ¿Por qué una familia gana tanto y otra, otro tanto? Dicen que es porque 


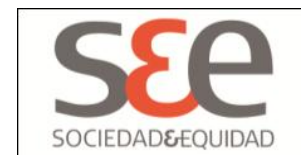

yo sólo tengo dos hijos, pero yo prefiero quedarme con dos [hijos] (Nerci, habitante de São Carlos).

Todas las familias deberían recibir lo mismo, incluso quienes tienen más hijos, porque a veces se gasta más con un solo hijo (Sandra).

Como lo evidencian estas opiniones, la diferencia de valores pagados por el PBF genera conflictos y disputas entre las beneficiarias que, en muchos casos, sienten que la situación es injusta porque el vecino o alguien conocido reciben más que ellas. El criterio más utilizado por ellas no es la condición de pobreza sino el "grado de necesidad".

\section{Conclusión}

Analizando los datos vinculados al Programa Bolsa Família, es notorio el fortalecimiento del Programa como política pública, pues demuestra una ampliación gradual del público destinatario, de las metas relacionadas con la atención de los beneficiarios, del presupuesto y de los valores pagos a las familias incluidas en el Programa. Esto contradeciría la tendencia histórica de discontinuidad y falta de perfeccionamiento de las políticas sociales. El PBF se ha consolidado en el escenario político y académico, nacional e internacional, y está en proceso de dejar de ser una política de gobierno para pasar a ser una política de Estado $^{26}$. Además, son visibles los efectos económicos que la distribución de renta mensual está generando en las familias más pobres.

Considerando el Programa Bolsa Família puesto en funcionamiento, se observa que la implementación y la ejecución diaria de esta política asumen elementos propios que se derivan de la estructura administrativa de cada municipio. En São Paulo, los registros no son continuos y la población no consigue identificar un local o personas con las cuales conversar para obtener informaciones sobre el PBF. Mientras que en São Carlos, la población identifica las instituciones públicas de asistencia social como lugares donde se puede "conseguir el Bolsa", aunque la concesión del beneficio se personifica en la figura de los técnicos que realizan los registros.

\footnotetext{
${ }^{26}$ Al respecto, Sposati (2010:269) sostiene: "se trata de la posibilidad, legitimidad y legalidad de pasar de un gobierno federal a otro, sin alteraciones de nombres, logotipos, etc. Esa posibilidad de permanencia [...]”"
} 


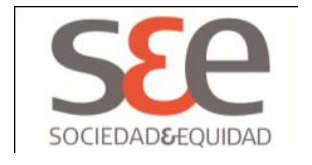

Finalmente, observando el PBF más de cerca, desde la mirada de aquellas que lo reciben, es posible identificar efectos positivos relacionados, en gran parte, con el alivio de la pobreza como resultado de un ingreso extra y "seguro" todos los meses para la familia. Pero, además de ese efecto, existen otros menos visibles, tales como la comprensión de que el beneficio es una ayuda que se "gana" del gobierno o que "cayó del cielo".

Aunque exista una prioridad para la mujer en la titularidad de esta política, el dinero proveniente del programa de transferencia de renta no es entendido por la beneficiaria como suyo, sino de los hijos y, por ello mismo, debe gastarse en o con ellos. Otra cuestión observada durante el trabajo de campo, es que el término "beneficiaria", ampliamente utilizado por el gobierno brasilero y por los investigadores, sencillamente no tiene ningún significado para las personas así clasificadas. Las titulares del Programa no asimilaron este término en su vocabulario: ellas simplemente "tienen el Bolsa".

Con respecto a la condición de pobreza, observamos que, no siempre las personas así clasificadas por el Estado se auto-identifican como pobres: la categoría pobreza no es una categoría estanca, sino que depende del contexto y de la situación en la cual se encuentra. Así, se puede afirmar que "se es pobre", como se puede afirmar que "pobre es el otro". La justificativa que las beneficiarias tienen para ser titulares del Bolsa Família es la "necesidad" y no la condición de pobreza.

En cuanto a la legitimidad de esta política, esta es en general, bien evaluada por las beneficiarias. Sin embargo hay críticas vinculadas principalmente a las diferencias en los valores pagos y denuncias de injusticia en casos en los cuales una persona recibe "más de lo que necesita".

Concluimos que, desplazando el foco de los números hacia la cotidianeidad de la política, otros elementos - más o menos significativos - surgen para evaluar una política pública. 


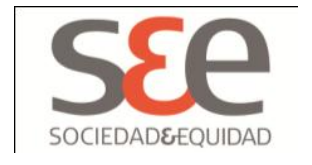

\section{Referencias Bibliográficas}

Araújo, C. (2007). Pobreza e programas de transferência de renda: concepções $e$ significados. Tesis de Doctorado. São Luís: Universidade Federal do Maranhão.

Baratta, T. (2008). Capacitação para implementação do Sistema Único de Assistência Social - SUAS e do Programa Bolsa Família - PBF. Rio de Janeiro: IBAM/Unicarioca; Brasília: MDS.

Brasil (2004). Decreto n. 5.209, de 17 de setembro de 2004. Regulamenta a Lei n.10.836, de 09 de janeiro de 2004, que cria o Programa Bolsa Família, e dá outras providências. Brasília: MDS.

Fonseca, A. (2010). As mulheres como titulares das transferências condicionadas: empoderamento ou reforço de posições de gênero tradicionais? Comunicación en XIII Congreso BIEN (Red Mundial de Renta Básica), São Paulo, Brasil.

Instituto Brasileiro de Análises Sociais e Econômicas (2008). Repercussões do Programa Bolsa Família na segurança alimentar e nutricional das famílias beneficiárias. Documento Síntese. Rio de Janeiro: IBASE.

Ministério de Desenvolvimento Social e Combate à Fome (2005). Programa Bolsa Família. Orientações para o Ministério Público. Secretaria Nacional de Renda e Cidadania. Brasília: SENARC/MDS.

. (2011). Bolsa Família: como participar. Disponible desde Internet en formato HTML en: http://www.mds.gov.br/bolsafamilia/como-participar.

Pereira, M. (2007). As representações da pobreza sob a ótica dos "pobres" do Programa Bolsa Família. Tesis de Maestría. Fortaleza: Universidade Federal do Ceará.

Rothstein, B. (1998). Just institutions matter: the moral and political logic of the universal welfare state. Cambridge: Universal Press.

Sen, A. (2000). Desenvolvimento como Liberdade. São Paulo: Companhia das Letras. 


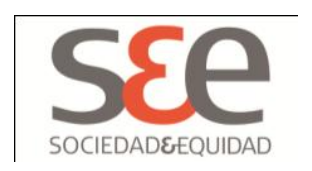

Silva, M., Yazbek, M, y Di Giovani, G. (2004). A política social no século XXI: a prevalência dos programas de transferência de renda. São Paulo: Cortez.

Soares, S et.al. (2010). Os impactos do benefício do Programa Bolsa Família sobre a desigualdade e pobreza. En Jorge Abrahão Castro y Lúcia Modesto (Eds.) Bolsa Família 2003 - 2010: avanços e desafios, v. 2 (pp. 27 -529), Brasília: IPEA.

Sposati, A (2010). Bolsa Família: um programa com futuro(s). En Jorge Abrahão Castro y Lúcia Modesto (Eds.) Bolsa Família 2003 - 2010: avanços e desafios, v. 2 (pp. 273- 299), Brasília: IPEA.

Telles, Vera da Silva (2001). Cidadania e Pobreza. São Paulo: Editora 34. 